\title{
Prevalence and Contributing Factors of Female Genital Cutting in Debaytilatgin District, Northwest Ethiopia
}

Yaregal Ejigu ${ }^{1}$, Gebeyaw Tiruneh ${ }^{2}$, Muleta Mekonnen ${ }^{3}$ and Getiye Dejenu Kibret ${ }^{*}$

${ }^{1}$ Ethiopian Health Insurance Agency, Ethiopia

${ }^{2}$ GAMBY College of Medical Sciences, Bahirdar, Ethiopia

${ }^{3}$ Health Sciences and Medical College, Debremarkos University, Ethiopia

*Corresponding author: Getiye Dejenu Kibret, Debre Markos University, Debre Markos, Amhara, Ethiopia; E-mail: dgetiye@gmail.com

Received date: Nov 07, 2014, Accepted date: Dec 17, 2014, Published date: Dec 23, 2014

Copyright: ( 2014 Kibret GD, et al. This is an open-access article distributed under the terms of the Creative Commons Attribution License, which permits unrestricted use, distribution, and reproduction in any medium, provided the original author and source are credited.

\begin{abstract}
It is estimated that more than 130 million girls and women alive today have undergone female genital mutilation. Female genital cutting predominately occurs in 28 African and the Middle East countries. The prevalence in Ethiopia is $74.3 \%$ and in Amhara region it accounts $68.5 \%$. This study was aimed to assess the prevalence and associated factors of female genital mutilation among women in the reproductive age group. The study used both quantitative and qualitative methods. The sample size for the survey was 730 and three focus group discussions were held among women in reproductive age group with daughters of under five years old. It was conducted by using a semi structured questionnaire and unstructured discussion guide. Logistic regression was used to see statistical associations. The prevalence of female genital mutilation among daughter less than five years was $62.7 \%$.
\end{abstract}

Educational level, age and circumcision status of women, availability of health education and not enforcement of legislations regarding Female genital mutilation were independent predictors of female genital mutilation.

The Regional health bureau, Zonal health department, District health office and health extension workers should work hard in addressing health education and creating awareness in the community regarding the devastating consequences and danger of female genital mutilation.

Keywords Female; Genital mutilation; Daughter

\section{Introduction}

Female genital mutilation (FGM), or female circumcision, includes all procedures involving partial or total removal of the external female genitalia or other injury to the female genital organs whether for cultural or other non-therapeutic reasons [1].

Four main types of FGM exist: Type one, Clitoridectomy involves the removal of the clitoral hood with or without removal of all or part of the clitoris. Type two, excision varies from the removal of the clitoris and/or clitoral prepuce to the removal of part or the entire clitoris together with part or all of the labia minora (the inner vaginal lips). Type three, infibulation involves the removal of the clitoris, the labia minora, and part of the labia majora after which the edges of the wound are sutured to leave a small opening (vaginal orifice). Type four (lastly), unclassified and the intermediate practice refers to the amputation of the clitoris and parts of the labia minora [2].

The health consequences vary according to the type and severity of the procedure performed. The immediate complications include severe pain, shock, hemorrhage, urine retention, and injury to adjacent tissue or death. Long-term consequences include urinary incontinence, painful sexual intercourse, sexual dysfunction, difficulties with childbirth, scaring and infertility [3].

Worldwide, between 100 and 140 million girls and women have experienced female genital cutting (FGC); it is estimated that at least 2 million girls are at risk from FGC every year. Type one and two are the most common forms of FGC, for approximately $80 \%$ of cases, while infibulations is found in around $15 \%$ of cases. Most women and girls with FGC live in 28 sub-Saharan African countries, with some living in Asia and the Middle East. Due to the migration of people who follow this tradition, however, FGC is today evident in Australia, Canada, the United States and in Europe [4]. The prevalence of FGC is vary from nation to nation such as Niger (5\%), Ghana (5\%), Benin (17\%), United Republic of Tanzania (18\%), Nigeria (19\%), Eritrea (89\%), Sudan (90\%), Egypt (97\%) and Ethiopia (80\%) [5].

The Ethiopian demographic and Health Survey of 2005 indicates that $74 \%$ of girls and women nationwide have been subjected to female genital mutilation and the Regional statistics of the prevalence from the survey were: Afar Region (91.6\%), Harare Region (85.1\%), Amhara Region (68.5\%), Oromia Region (87.2\%), Addis Ababa City (65.7\%), Somali Region (97.3\%), Beneshangul Gumuz Region(67.6\%), Tigray Region (29.3\%), Southern Region (27.1\%) and Dire Dawa Region (92.3\%) [6]. The factors responsible for FGC practices are belief, religion, education, and tradition, gender- related factors, health and Socio-economic factors $[7,8]$.

Although the Health extension works are available in each Kebeles, the national as well as the regional female genital cutting prevalence is still high and studies on female genital cutting practice are scarce in the study area.

Therefore, to fill the gap this study was aimed to measure prevalence and associated factors for female genital cutting. The result of this study can help program planners, policy makers and health care providers to focus on the facts or problems and it will also remind the 
regional and district health planners to visualize the extent of the problem in terms of its significant life-long negative health impacts and special health care needs of victims.

\section{Objective}

The main aim of this study was to determine the prevalence and identify contributing factors of female genital cutting in Debaytilatgin District, March 2013

\section{Methods}

\section{Study design}

Community based cross sectional study design using both quantitative and qualitative methods was implemented.

\section{Study area and period}

The study was conducted in Debaytilatgin District northwest Ethiopia from 16-30 of March 2013.

\section{Population}

The source population for the survey was all women in reproductive age group (15-49 ages) residing in the District and the study population were all women in reproductive age group. For the focus group discussion women in the reproductive age group in the selected Kebele with daughters of less than five years old were involved.

\section{Sample size determination}

Sample size was determined using a single population proportion formula, using the proportion $(\mathrm{P})$ of $(68.5 \%)$ taken from the regional prevalence [6].

$$
\mathrm{n}=\frac{\mathrm{Za} / 2^{2^{*} \mathrm{P}(1-\mathrm{P})}}{\mathrm{d}^{2}}
$$

Where:

$\mathrm{n}=$ sample size

$\mathrm{Za} / 2=$ significance level at $95 \%$ confidence interval two sided

$\mathrm{P}=$ Prevalence of female genital mutilation in Amhara Region $=$ $68.5 \%$

\section{$\mathrm{d}=$ the margin of error}

Considering design effect of 2 and non-response rate of $10 \%$, the total sample size for the quantitative part was 664 . Three focus group discussions were held among women in reproductive age group each group comprising 6-8 women.

\section{Sampling technique and procedures}

Multistage sampling method was used, five out of 25 Kebeles in the District were taken using Simple random sampling method and the households in each selected Kebeles were chosen by systematic random sampling method by determining a central point in each Kebele and rotating a pen to indicate a random direction for data collection. The total sample size was proportionally allocated to each of the kebeles based on their population size. In cases of households with more than one woman eligible, lottery method was used for selection of interviewee. Participant in the FGDS from the selected kebeles were taken from women in the reproductive age group (15-49 years of age), traditional circumcisers, and local administrators using purposive sampling method in the selected Kebeles by the supervisor and the principal investigator before two week from the interview.

\section{Data collection instruments}

Semi structured questionnaires were prepared first in English and then translated in to the local language; Amharic. The interview process was administered in Amharic for ease of communication. Data were collected by recruiting seven trained health workers. For the qualitative study, unstructured discussion guide was developed containing important points to explore the perception and understanding of the people towards female genital cutting and the discussions were recorded by using tape-recorder after getting consent from each participants. A total of 4 FGDs were performed each FGD containing 8-12 participants. The time taken for discussion for each FGD ranges one hour to one and half hours. The principal investigator was a modulator and a note taker was recruited.

\section{Eligibility criteria}

Women in reproductive age group who had daughters less than five years of age were included in the study and women who were seriously ill during data collection were excluded.

\section{Variables of the study}

Dependent variable: Female genital cutting

Explanatory variables: Age, educational status, religion, believe, harmful traditions/custom, ethnicity, marital status, occupation, Income, health education availability, mother circumcision status, husband opinion, local low, perception of health problems.

Quality assurance: The quality of data was assured by properly designing and pre-testing of the questionnaire, one day training of the interviewers, supervisors and note takers was given on the on the data collection tools and the approach that they had to follow. Pretest for both quantitative data collection tools and FGDs guide was done in kebeles out of the actual data collection area. Furthermore, supervisors and the principal investigator checked the collected data carefully on daily basis for their completeness, accuracy and clarity.

Data processing and analysis: The quantitative data was coded and entered by using EPI-data version 3.1 and analyzed using SPSS version 16 statistical software. Bivariate and multivariable logistic regression was done to assess the relative effect of varies explanatory variables on the dependent variables.

For the qualitative data, thematic content analysis was applied used, through identifying and categorizing patterns in the data. After having transcribed the whole data set, an in-depth analysis was carried out, through careful reading of the data.

Operational definitions: Female genital mutilation (FGM), or female circumcision, includes all procedures involving partial or total removal of the external female genitalia or other injury to the female genital organs.

Kebele: The lowest Government administrative hierarchy that exists next to woreda. 
Ethical consideration: Ethical clearance was obtained from the ethical committee of Debremarkos University. The study participants were informed about the objective, rationale and expected outcomes of the study and oral consent was obtained either to participate or refuse for the interview.

\section{Result}

\section{Socio demographic characteristics}

Data were obtained from 730 respondents making the response rate $100 \%$. The age of the respondents range from 15-49 years, the mean $( \pm$ SD) age of study participants was $29( \pm 7)$ years. Majority of women 710 (97.3\%) were Amhara and the rest Tigrie and Oromo. Majorities of the women 705 (96.6\%) were Orthodox Christian and the rest 25 (3.4\%) were Muslim and other Christianity followers. The great majority of women $640(87.7 \%)$ were married (Table 1$)$.

\section{Reproductive health status}

The mean age of study subjects at first marriage and at first pregnancy was $10.1( \pm 3.8)$ and $17.4( \pm 3.1)$ years, respectively. Of the total study participants, $567(77.7 \%)$ were genitally circumcised and also whose under five years daughters $458(62.7 \%)$ were genitally circumcised. This idea was in agreement with qualitative part of the study, majority of women themselves and their daughter under five years were circumcised. For example one discussant was 25 years old farmer said that "female genital cutting should be practiced because it helps women to be respected by the society unless she was blamed (criticized) by the community so called Difin Qil or Woshela" (offensive insulting term for uncircumcised). One 34 years old farmer discussant said that "I was not circumcised because I was Yemariam Girz (naturally circumcised) (Table 2).

\begin{tabular}{|l|l|l|}
\hline Variables & Frequency & $\%$ \\
\hline Age & & \\
\hline $15-24$ & 338 & 46.3 \\
\hline $25-34$ & 194 & 26.6 \\
\hline $35-49$ & &
\end{tabular}

\section{Marital status}

\begin{tabular}{|l|l|l|}
\hline Single & 18 & 2.5 \\
\hline Married & 640 & 87.7 \\
\hline Divorced & 68 & 9.3 \\
\hline Widowed & 4 & 0.5 \\
\hline
\end{tabular}

\section{Educational status}

\begin{tabular}{|l|l|l|}
\hline Can't read and write & 491 & 67.3 \\
\hline Read -write & 101 & 13.8 \\
\hline Primary school (1-8 and above) & 138 & 18.9 \\
\hline Occupation & 710 & 97.3 \\
\hline Farmer & 12 & 1.6 \\
\hline Government employer & & \\
\hline
\end{tabular}

\begin{tabular}{|l|l|l|}
\hline Students & 8 & 1.1 \\
\hline \multicolumn{2}{|l|}{ Income per month } & 258 \\
\hline Less than 555 birr & 343 & 35.3 \\
\hline $556-1233$ birr & 125 & 47 \\
\hline More than 1233 birr & 4 & 17.1 \\
\hline Unknown & & 0.5 \\
\hline
\end{tabular}

Table 1: Socio-demographic characteristics of the study participants, Debaytlatgin District Northwest Ethiopia, March 2013

\begin{tabular}{|l|l|l|}
\hline Variables & Frequency & $\%$ \\
\hline Less than five years daughters circumcised & \multicolumn{2}{|l|}{} \\
\hline Yes & 458 & 62.7 \\
\hline No & 272 & 37.3 \\
\hline Age of daughters circumcised & \multicolumn{2}{l|}{} \\
\hline Less than one year & 439 & 95.8 \\
\hline One to two year & 18 & 3.9 \\
\hline Three to four and eleven months & 1 & 0.2 \\
\hline Place of circumcision & \multicolumn{2}{|l}{} \\
\hline Own home & 444 & 96.9 \\
\hline Another home & 11 & 2.4 \\
\hline Home of circumcisers & 3 & 0.7 \\
\hline
\end{tabular}

Table 2: Circumcision practice of the study participants, Debaytlatgin District March 2013

The qualitative study also supported above figure (Figure 1), almost all participants gave reason why female genital cutting practice with in the society for different reasons. These were: traditional/custom, simple to give births, simple to dis-verge, it makes to be happy during sex, it reduces the bad believes of the society because female genital cutting is our tradition/custom that comes from their ancestors, they said also it has to be kept as it is in the future.

\section{Factors associated with female genital cutting Practices}

Multivariate logistic regression analysis was used when bivariate logistic regression analysis was $\mathrm{P}<0.2$. The participants who had age 15-24 years were less likely to practiced female genital cutting than those with age of $34-49$ years [AOR $(95 \% \mathrm{CI})=.20(.06-.64)]$. Female genital cutting practice of the study participants had also a significant association with their schooling. Women who had not attend a school were 5.43 times practiced than who had attends formal school [AOR $(95 \% \mathrm{CI})=5.43(1.88-15.68)]$.

Women who had previously circumcised were 3.45 times practices their daughters circumcision than who had not circumcised [AOR (95\% CI $=3.45(1.35-8.79)]$. The participants who knew female circumcision cause health problems were less likely to practiced female genital cutting than those who didn't [AOR $(95 \% \mathrm{CI})=.01(.005-.04)]$. 
Citation: Kibret GD, Ejigu Y, Tiruneh G, Mekonnen M (2014) Prevalence and Contributing Factors of Female Genital Cutting in Debaytilatgin

Page 4 of 6

Individuals who had not taken health education about female genital cutting malpractices were 5.22 times more likely to practice female genital cutting than those who had taken health education [AOR $(95 \% \mathrm{CI})=5.22(2.20-12.36)]$ (Table 3).

Bivariate and multivariable logistic regression analysis identified women's religion; ethnicity, marital status and income were not showed significant association towards female genital cutting.

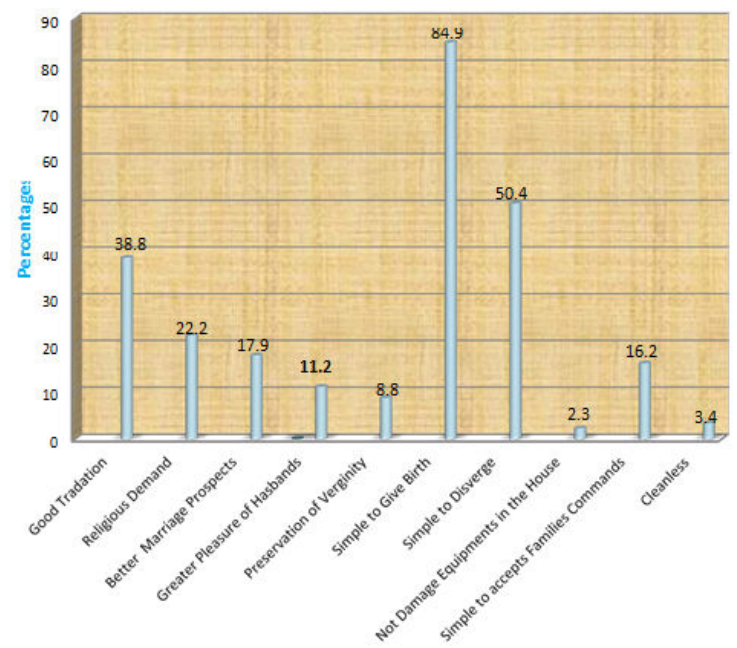

Figure 1: The main reasons for female genital cutting practices, Debaytilatgin District, Ethiopia.

\section{Discussion}

The practice of female genital cutting is a very deeply rooted harmful tradition that dates back centuries in most African and some Arabian countries.

This study had tried to assess the practices and associated factors of female genital cutting among individuals of age group 15-49 years women who had under five year daughters. In this study, it was found that $62.7 \%$ of the daughters who were under five year had undergone female genital cutting. This figure if slightly lower compared to Amhara region prevalence EDHS report of Ethiopia, which was only $68.5[6,9,10]$. On the other hand, this study figure was considerably higher when compared to study conducted in Somali refugees in Ethiopia, which was only $30 \%$ of daughters, were circumcised and lower than when compared to study conducted in Egypt which was $77.3 \%$ of daughters, were circumcised [11-20] . This might be due to female genital cutting practices is more accepted in amhara region as good practice than in tigray region.

In this study, $77.7 \%$ of women were circumcised. This figure is higher than the prevalence of studies done in Amhara, Addis Ababa, Benshangul Gumiz, Tigray and Southern Region but lower than Afar, Harare, Oromia, Somali, Dire Dawa Region, East Harargie, Eritrea, Sudan, and Egypt [5,6,21].

Circumcised women were significantly associated with daughters genital cutting practices in this study compared to non-circumcised women. Women had circumcised one or more of their daughters and majority of women were circumcised themselves. This finding is in line with other studies done in Ethiopia [21].

\begin{tabular}{|c|c|c|c|c|}
\hline \multirow[t]{2}{*}{ Variables } & \multicolumn{2}{|c|}{$\begin{array}{l}\text { Daughters less than Five years } \\
\text { Circumcised }\end{array}$} & \multirow[t]{2}{*}{ Crude OR $(95 \% \mathrm{Cl})$} & \multirow[t]{2}{*}{ Adjusted OR $(95 \% \mathrm{Cl})$} \\
\hline & Yes & No & & \\
\hline \multicolumn{5}{|l|}{ Age } \\
\hline $15-24$ & 80 & 118 & $.13(.08-.20)$ & $.20(.06-.64)$ \\
\hline $25-34$ & 215 & 123 & $.32(.21-.50)$ & $.52(.17-1.45)$ \\
\hline $35-49$ & 163 & 31 & 1.00 & 1.00 \\
\hline \multicolumn{5}{|l|}{ Educational status } \\
\hline Cannot read/write & 383 & 109 & $28.37(16.14-49.89)$ & $5.43(1.88-15.68)$ \\
\hline Read/write & 38 & 62 & $9.12(4.75-17.50)$ & $3.10(.88-10.97)$ \\
\hline Primary (1-8) and above & 37 & 101 & 1.00 & 1.00 \\
\hline \multicolumn{5}{|l|}{ Women circumcision } \\
\hline Yes & 379 & 192 & $1.41(.99-2.003)$ & $3.45(1.35-8.79)$ \\
\hline No & 79 & 80 & 1.00 & 1.00 \\
\hline \multicolumn{5}{|l|}{ FGC should continue } \\
\hline Yes & 430 & 19 & $23.04(15.42-34.41)$ & $15.37(5.88-40.20)$ \\
\hline No & 28 & 253 & 1.00 & 1.00 \\
\hline
\end{tabular}




\begin{tabular}{|c|c|c|c|c|}
\hline Favor & 345 & 38 & $18.80(12.56-28.14)$ & $.90(.31-2.60)$ \\
\hline Oppose and no opinion & 113 & 234 & 1.00 & 1.00 \\
\hline \multicolumn{5}{|l|}{ The way to eradicate FGC } \\
\hline Enforced legislation & 45 & 209 & $.04(.02-.10)$ & $.03(.003-.31)$ \\
\hline $\begin{array}{l}\text { Educational campaign to women, TBA, } \\
\text { circumciser and community. }\end{array}$ & 379 & 57 & $1.17(.47-2.92)$ & $.24(.03-2.07)$ \\
\hline Improvement of status of women & 34 & 6 & 1.00 & 1.00 \\
\hline \multicolumn{5}{|l|}{ Health education } \\
\hline Yes & 47 & 217 & 1.00 & 1.00 \\
\hline No & 411 & 55 & $34.5(22.61-52.65)$ & $5.23(2.20-12.36)$ \\
\hline \multicolumn{5}{|l|}{ Against the low } \\
\hline Yes & 81 & 133 & 1.00 & 1.00 \\
\hline No & 377 & 139 & $4.45(3.18-6.24)$ & $2.73(1.17-6.41)$ \\
\hline
\end{tabular}

Table 3: Association between female genital cutting and selected variables in Debaytlatgin District, March 2013

Educational status and age had shown statistically significant association with female genital cutting practices in this study. Individuals with educational status of primary and above were less likely to practice than those who had no formal education. This finding is in line with other studies done in Ethiopia [6,19,21]. Women with the age group of 15-24 years were also less likely to practice female genital cutting than age group 34-49 years, so it increased with age. This finding was in line with other studies done in Ethiopia [20]. It might be right reason for seeking female genital cutting in this study was for age younger to older traditional malpractices high but educational status low due to this reason female genital cutting practices increased with age or time gap.

Most respondents were operated on by traditional circumcisers and traditional birth attendants, which is similar to the findings in Somali refugee of Ethiopia [20]. The main reason to circumcise the daughters was easy to give birth, easy to disverge and tradition/customs. The same findings were observed by a study in Egypt [13] and Ethiopia $[20,21]$.

Health education was significantly associated with female genital cutting. This study found that $17.8 \%$ of those who had taken health education practiced female genital cutting with compare to $82.2 \%$ of those who didn't get health education about female genital cutting malpractices. Even though, health extension workers found in each Kebele, this might be a gap to give health education to the community. Another possibly explanation might be health extension workers and women affaire office might not give due attention to the issue of female genital cutting practice and out comes or consequences in the community.

Enforcement legislation was mentioned as the best way to stop female genital cutting practices and significantly associated with it. In this study $37.8 \%$ of respondents circumcised their daughters and knew of FGC was a criminal compare to $73.1 \%$ was circumcised their daughter did not know about it. This might be due to every people were under the rule of the low of the country and afraid of it. The Ethiopian government modified its legislation by making FGC a criminal act. However, Ethiopia has had problems in implementing the law because no complaints were reported or filed until the end of 2008. This indicates a low level of community involvement, awareness about the new law and the information dissemination was low in the community [21].

\section{Conclusion and Recommendation}

Female genital cutting practice was very high.

Educational level, age and circumcision status of women, availability of health education and not enforcement of legislations regarding female genital mutilation were independent predictors of female genital mutilation [22].

The Regional health bureau, Zonal health department, District health office and health extension workers should work hard in addressing health education and creating awareness in the community regarding the devastating consequences and danger of female genital mutilation. There should be a maximum effort by the health care providers, religious leaders, community and women's leaders, nongovernmental organizations and international agencies against the practices by implementing IEC and BCC in the community.

\section{References}

1. Leye E, Powell RA, Nienhuis G, Claeys P, Temmerman M (2006) Health Care in Europe for Women with Genital Mutilation. Health Care Women Int 27: 362-378.

2. Sakeah E, Beke A, Doctor HV, Hodgson AV (2006) Males' preference for circumcised women in Northern Ghana. Afr J Reprod Health 10: 37-47.

3. Oduro AR, Ansah P, Hodgson A, Afful TM, Baiden F, et al. (2006) Trends in the prevalence of female genital mutilation and its effect on delivery outcomes in the Kassena-Nankana District of Northern Ghana. Ghana Med J 40: 87-92.

4. Monjok E, Essien EJ, Holmes L Jr (2007) Female Genital Mutilation: Potential for HIV Transmission in sub-Saharan Africa and Prospect for Epidemiologic Investigation and Intervention. Afr J Reprod Health 11: $33-42$. 
Citation: Kibret GD, Ejigu Y, Tiruneh G, Mekonnen M (2014) Prevalence and Contributing Factors of Female Genital Cutting in Debaytilatgin District, Northwest Ethiopia. Clinics Mother Child Health 11: 167. doi:10.4172/2090-7214.1000167

Page 6 of 6

5. Nour NM (2008) Female Genital Cutting: A Persisting Practice. Rev Obstet Gynecol 1: 135-139

6. (2006) Central Statistical Agency (CSA) [Ethiopia] and ORC Macro.

7. Tag-Eldin MA, Gadallah MA, Al-Tayeb MN, Abdel-Aty M, Mansour E, et al. (2008) Prevalence of female genital cutting among Egyptian girls. Bulletin of the World Health Organization 86: 269-274.

8. Kandil M (2012) Female circumcision: Limiting the harm. F1000Res 1: 23.

9. (2010) WISE Muslim Women's Shura Council. Female Genital Cutting: Harmful and Un- Islamic.

10. (2010) Population Reference Bureau. Female Genital Mutilation/Cutting: Data and Trends Update 2010.

11. Kaplan-Marcusán A, Fernández del Rio N, Moreno-Navarro J, CastanyFàbregas MJ, Nogueras MR, et al. (2010) Female Genital Mutilation: perceptions of healthcare professionals and the perspective of the migrant families. BMC Public Health 10: 193.

12. Kolawole AOD, Kwaak AV de (2010) A Review of determinants of female genital mutilation in Nigeria. Journal of Medicine and Medical Sciences 1: 510-515

13. Emam E, EL-Maghawri A, Labeeb S (2011) Cultural awareness about female genital mutilation among female employees of Minia University: Journal of American Science 7: 611-617.

14. Kaplan A, Hechavarría S, Martín M, Bonhoure I (2011) Health consequences of female genital mutilation/cutting in the Gambia, evidence into action. Reproductive Health 8: 26.
15. Karmaker B, Kandala NB, Chung D, Clarke A (2011) Factors Associated with Female Genital Mutilation in Burkina Faso and its Policy Implications. Int J Equity Health 10: 20.

16. Bedri NM (2012) Ending FGM/C through Evidence Based Advocacy in Sudan.

17. Okwudili OA, Chukwudi OR (2012) Urinary genital tract obstruction as a complication of female genital mutilation: case report and literature review. J Surg Tech Case Report 4: 64-66.

18. Bjälkander O, Bangura L, Leigh B, Berggren V, Bergström S, et al. (2012) Health complications of female genital mutilation in Sierra Leone. Int J Womens Health 4: 321-331.

19. Mariam AG, Hailemariam A, Belachew T, Michael KW, Lindstrom D, et al. (2009) Support for the continuation of female genital mutilation among adolescence in Jimma Zone, Southwest Ethiopia. Ethiop J Health Sci 19: 119-129.

20. Mitike G, Deressa W (2009) Prevalence and associated factors of female genital mutilation among Somali refugees in eastern Ethiopia: a crosssectional study. BMC Public Health 9: 264.

21. Yirga WS, Kassa NA, Gebremichael MW, Aro AR (2012) Female genital mutilation: prevalence, perceptions and effect on women's health in Kersa district of Ethiopia. Int J Womens Health 4: 45-54.

22. Abdulcadir J, Margairaz C, Boulvain M, Irion O (2011) Care of women with female genital mutilation/cutting. Swiss Med Wkly 140: w13137. 